\title{
Erratum to: ARB-Based Single-Pill Platform to Guide a Practical Therapeutic Approach to Hypertensive Patients
}

\author{
Massimo Volpe • Alejandro de la Sierra • \\ Reinhold Kreutz $\cdot$ Stéphane Laurent . \\ Athanasios J. Manolis
}

Published online: 29 March 2014

(C) Springer International Publishing Switzerland 2014

\section{Erratum to: High Blood Press Cardiovasc Prev DOI 10.1007/s40292-014-0043-6}

In Fig. 2 of the article, when referring to Coronary artery disease with Grade 2 or Grade 3 hypertension the abbreviation "OLM" was used instead of "OM" to indicate olmesartan, as defined in the footnote. In addition, referring to Nephropathy with Grade 1 hypertension, "2040 mg" should be "20-40 mg".

This has been corrected in the new Fig. 2 (see below).

The authors apologise for this oversight.

The online version of the original article can be found under doi:10.1007/s40292-014-0043-6.

M. Volpe $(\bowtie)$

Department of Clinical and Molecular Medicine, School of

Medicine and Psychology, Sapienza University of Rome, Via di

Grottarossa 1035-39, 00189 Rome, Italy

e-mail: massimo.volpe@uniroma1.it

M. Volpe

IRCCS Neuromed, Pozzilli, Italy

A. de la Sierra

Department of Internal Medicine, Hospital Mútua Terrassa,

University of Barcelona, Terrassa, Spain

R. Kreutz

Department of Clinical Pharmacology and Toxicology Charité,

Universitätsmedizin Berlin, Charitéplatz 1,

10117 Berlin, Germany

S. Laurent

Department of Pharmacology and INSERM U 970, European Georges Pompidou Hospital, Université Paris-Descartes and Assistance Publique Hôpitaux de Paris, Paris, France

A. J. Manolis

Cardiology Department, Asclepeion General Hospital,

Athens, Greece 


\begin{tabular}{|c|c|c|c|}
\hline Overt organ damage & $\begin{array}{c}\text { Grade } 1 \\
\text { SBP 140-159 } \\
\text { or DBP 90-99 }\end{array}$ & $\begin{array}{c}\text { Grade 2 } \\
\text { SBP 160-179 } \\
\text { or DBP 100-109 }\end{array}$ & $\begin{array}{c}\text { Grade } 3 \\
S B P \geq 180 \\
\text { or DBP } \geq 110\end{array}$ \\
\hline Atrial fibrillation ${ }^{a}$ & OM 20-40 mg & OM/HCTZ 20-40/12.5 mg & OM/HCTZ 20-40/25 mg \\
\hline $\begin{array}{l}\text { Nephropathy (CKD stage }>3 \text { ) } \\
\text { eGFR }<30 \mathrm{ml} / \mathrm{min} / 1.73 \mathrm{~m}^{2}\end{array}$ & OM $20-40 \mathrm{mg}^{\mathrm{g}, \mathrm{h}}$ & $\mathrm{OM} / \mathrm{AML} 40 / 5 \mathrm{mg}^{\mathrm{g}, \mathrm{h}}$ & OM/AML 40/10 mg ${ }^{g, h}$ \\
\hline Coronary artery disease $^{c}$ & OM 10-20 mg & OM/AML $20-40 / 5 \mathrm{mg}^{\mathrm{d}}$ & OM/AML $40 / 10 \mathrm{mg}^{d}$ \\
\hline $\begin{array}{l}\text { Previous stroke or transient ischemic } \\
\text { attack }\end{array}$ & OM 10-20 mg & OM/AML $20-40 / 5 \mathrm{mg}^{d}$ & OM/AML $40 / 10 \mathrm{mg}^{\mathrm{d}}$ \\
\hline Heart failure with reduced $\mathrm{EF}^{f}$ & OM/HCTZ 10-20/12.5 mg ' & OM/HCTZ 20-40/25 mg ${ }^{d, i}$ & OM/HCTZ 40/25 mg d, i \\
\hline
\end{tabular}

Fig. 2 Platform for treating hypertensive patients who have overt organ damage. Patients continue to receive treatment for underlying conditions according to the appropriate guidelines. Avoid dual RAS therapy. Change therapy if ineffective or not tolerated. $A M L$ amlodipine, HCTZ hydrochlorothiazide, $L V E F$ left ventricular ejection fraction, $O M$ olmesartan medoxomil. ${ }^{\mathrm{a}}$ Guidelines for the management of atrial fibrillation: the Task Force for the Management of Atrial Fibrillation of the European Society of Cardiology (ESC) [21]. ${ }^{\mathrm{b}}$ A European Renal Best Practice (ERBP) position statement on the Kidney Disease: Improving Global Outcomes (KDIGO) Clinical Practice Guideline for the Management of Blood Pressure in Non- dialysis-dependent Chronic Kidney Disease: an endorsement with some caveats for real-life application [19]. ${ }^{\text {c}} 2013$ ESC guidelines on the management of stable coronary artery disease [22]. ${ }^{\mathrm{d}}$ Consider single-pill triple combination treatment if $\mathrm{BP}$ is not at target. ${ }^{\mathrm{e}} \mathrm{ESO}$ Guidelines for management of ischaemic stroke and transient ischaemic attack 2008 [23]. ${ }^{\mathrm{f}} \mathrm{ESC}$ Guidelines for the diagnosis and treatment of acute and chronic heart failure 2012 [24]. ${ }^{\mathrm{g}}$ Initiate $\mathrm{OM}$ at low doses $(10 \mathrm{mg})$ and uptitrate only with close monitoring of serum potassium. ${ }^{\mathrm{h}}$ Consider adding loop diuretics for volume overload. ${ }^{\mathrm{i}}$ Consider replacing HCTZ with a loop diuretic for symptoms of volume overload 